\title{
Warum die Direktwahl des Bundespräsidenten nichts kuschelweich Demokratisches ist
}

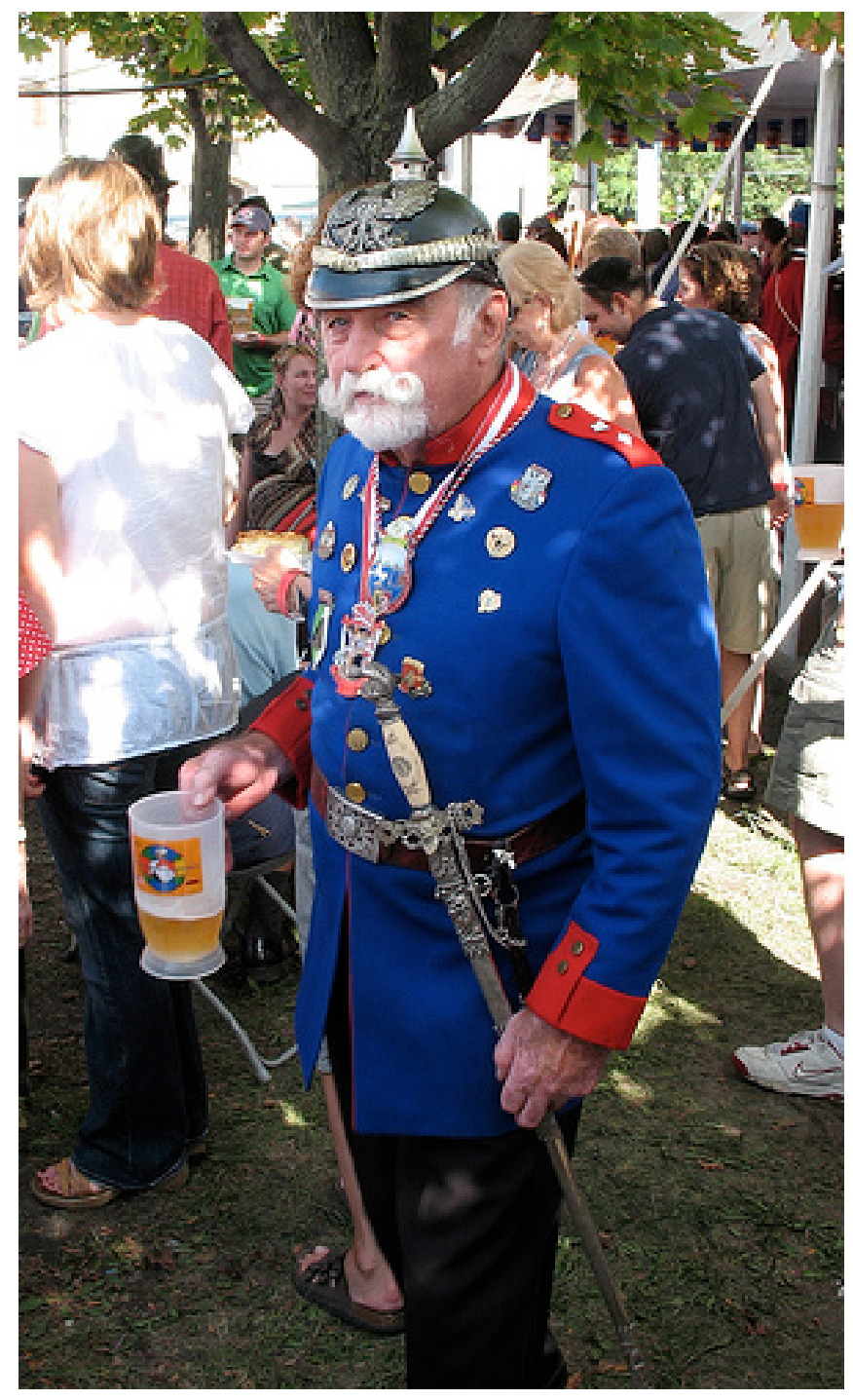

der kläglicheren Momente in der an kläglichen Momenten nicht armen

Präsidentschaft von Horst Köhler war der Tag fast genau vor drei Jahren, als Köhler bei "Christiansen" vorschlug, den Bundespräsidenten künftig direkt vom Volk wählen zu lassen.

Das Thema kommt immer wieder. Es ist der Wiedergänger der verfassungspolitischen Debatte.

Das liegt wahrscheinlich daran, dass man mit dem Vorschlag so wunderbar hammbrücherisieren kann: Das Staatsoberhaupt vom Volk wählen lassen, wer kann denn 
da dagegen sein? Sie klingt so kuschelweich demokratisch, diese Forderung, man kann so große runde Augen machen dabei. Sie klingt so lauter und so rein und dann auch irgendwie aufrecht und mutig, zumal dann die immer gleichen finsteren konservativen Staatsrechtler strikt dagegen sind, und das ist um so angenehmer, als die Forderung völlig risikolos ist, weil sie niemals ernsthaft umgesetzt werden wird, weil 30 Sekunden verfassungspolitisches Nachdenken ausreichen, um sie als völlig irre zu verwerfen.

\section{Der Staats-Liturg}

Der Bundespräsident hat in der bundesrepublikanischen Verfassungswirklichkeit politisch nicht viel zu melden. Sein Job ist ein liturgischer: Er hat im Wesentlichen an einigen Stellen im Regierungs- und Gesetzgebungsablauf staatsrituelle Handlungen zu vollziehen und ein feierliches Gesicht dabei zu machen.

Das muss aber nicht so bleiben. Es kommt, wie so oft, darauf an, was man daraus macht. Schon Konrad Adenauer ließ sich 1959 von den unausgeschöpften Möglichkeiten dieses Amtes verlocken, sich selbst als Nachfolger von Theodor Heuss ins Gespräch zu bringen.

An Ansatzpunkten im Grundgesetz fehlt es nicht: Der Bundespräsident schlägt dem Bundestag den Kanzler zur Wahl vor. Er ernennt die Minister, Beamten und Richter. Er vertritt den Bund völkerrechtlich und schließt Verträge mit auswärtigen Staaten. Er unterzeichnet alle Gesetze und überprüft sie auf ihr verfassungskonformes Zustandekommen. Er löst unter bestimmten Bedingungen den Bundestag auf.

Da ließe sich schon etwas damit anstellen. Es müsste nur etwas dazukommen. Etwas, das hilft, die über 60 Jahre etablierten liturgischen Einhegungen zu durchbrechen. Etwas, das man den Staatsrechtlern und Verfassungsrichtern entgegenhalten kann als Argument, warum ihre bisherige Auslegung der Art. 59 ff. GG keine Grundlage mehr hat.

Und das wäre die direkte Wahl des Bundespräsidenten. Der Inhaber dieses Amtes wäre dann der am stärksten demokratisch Legitimierte im gesamten Verfassungsgefüge der Bundesrepublik Deutschland. Was will man inm entgegenhalten, wenn er sich - sagen wir - aus politischen Gründen und mit verfassungsrechtlichen Argumenten weigert, ein ihm nicht genehmes Gesetz auszufertigen? Oder wenn er nach der nächsten Bundestagswahl die Suche nach einem mehrheitsfähigen Kanzlerkandidaten, den er dem Bundestag zur Wahl vorschlägt, selber in die Hand nimmt?

\section{Warum Lafontaine und Gauweiler so glühend dafür sind}

Nun muss man die Vorstellung eines derart mächtigen Staatsoberhaupts keineswegs für schlimm halten. Oskar Lafontaine ist sehr für die Direktwahl des Bundespräsidenten und klug genug, die Folgen zu überblicken. Das gleiche gilt für Peter Gauweiler, auch er ein heftiger Befürworter der Direktwahl. (Bei Guido Westerwelle, der auch sehr dafür ist, bin ich nicht so sicher.) 
Ein direkt gewählter Bundespräsident wäre ein starker nationaler Führer, von seinem Volk mit politischer Macht ausgestattet. Genau das, was Lafontaine und Gauweiler prima fänden.

Die Folge wäre ein gigantischer Renationalisierungs-Schub. Die Folge wäre die Berliner Republik, von der nach 1990 manche träumten und die es gottlob nie gegeben hat.

Darüber sollten sich die Hamm-Brücherisierer klar werden, ob es das ist, was sie wollen. 